\title{
O FINANCIAMENTO DA EDUCAÇÃO INFANTIL NÃO É BRINCADEIRA DE CRIANÇA: ENTRE A AUSÊNCIA NO FUNDEF E A INSUFICIÊNCIA DO FUNDEB?**
}

Wellington Ferreira de Jesus**

\section{RESUMO}

O presente trabalho, uma pesquisa exploratória, fundamentada no levantamento dos dados agregados disponíveis na Secretaria do Tesouro Nacional, Ministério da Educação, Inep, levantamento estatístico do Ibge e literatura pertinente, analisou os investimentos em educação infantil, no ano de 1996, ano da implantação do Fundef até a aprovação da Medida Provisória 339/2006 pela Câmara em abril de 2007, objetivando oferecer subsídios para responder algumas questões: Qual o custo do aluno na educação infantil brasileira? Quais as responsabilidades dos entes federativos no desenvolvimento e na expansão da modalidade? O Fundeb será um aliado satisfatório ou apenas um paliativo no financiamento da educação infantil? Considera-se, ao final, a necessidade de transformar a educação infantil em uma política pública permanente e o respeito aos preceitos constitucionais de alocação de verbas.

Palavras-chave: Educação infantil. Financiamento da educação. Fundeb. Fundef.

\section{INTRODUÇÃO}

No final da década de 1990 foram realizados esforços tanto de setores organizados da sociedade quanto de gestores públicos, pais e, especialmente, de educadores no sentido do reconhecimento da educação infantil como uma atividade fundamental no desenvolvimento das crianças. Um dos objetivos mais significativos era o de transformar a

\footnotetext{
* Artigo recebido em 24/06/2008 e aprovado em 17/10/2008.

** Professor no ensino médio da rede pública do DF e na educação superior privada. E-mail: wellingtonfj@gmail.com
} 
educação infantil em uma política pública educacional de caráter permanente, retirando-se o caráter emergencial e assistencialista que permeou esta modalidade ao longo da história brasileira.

Contudo, faz-se necessário erradicar por completo o estereótipo que a modalidade ainda carrega, particularmente, para a maioria dos setores sociais de baixo status socioeconômico. Em outras palavras, o "depósito de crianças" onde mães e pais deixam seus filhos para buscálos no momento de volta da jornada diária de trabalho.

A Constituição Federal (CF), de 1988, e a Lei das Diretrizes e Bases da Educação Nacional, de 1996, definem a educação a partir do construto de "direito público e subjetivo", além disso, sob a co-responsabilidade do Estado e da família. O Plano Nacional de Educação (PNE) definiu a necessidade de inclusão das creches e pré-escolas no contexto da universalização do ensino básico no país. Contudo, dados da Pesquisa Nacional por Amostragem Domiciliar (PNAD), realizada em 2005, demonstram que apenas $11,7 \%$ das crianças de 0 a 3 anos e $68,4 \%$ na faixa etária de 04 a 06 anos são atendidas por creches e pré-escolas, tanto na rede pública como na privada.

Considerando também o fato de que toda a educação pública demanda custos e, no emaranhado que constitui o financiamento da educação nacional, parece que sobram discursos e estão ausentes as verbas públicas para a modalidade. Sobretudo, se considerarmos que a educação infantil necessita de um maior aporte de recursos quando se compara o conjunto do ensino básico no país.

O presente trabalho, uma pesquisa exploratória, fundamentada no levantamento dos dados agregados disponíveis na Secretaria do Tesouro Nacional (STN), Ministério da Educação (MEC), Inep, levantamento estatístico do Ibge e em bibliografia pertinente, procurou analisar os investimentos em educação infantil, no período 1996, ano da implantação do Fundo de Manutenção do Ensino Fundamental e Valorização do Magistério até a aprovação da Medida Provisória (MP) 339/2006 pela Câmara em abril de 2007, ${ }^{1}$ objetivando oferecer subsídios para responder algumas questões: Qual o custo do aluno na educação infantil brasileira? Quais as responsabilidades dos entes federativos no desenvolvimento e na expansão da modalidade? O Fundeb será um aliado satisfatório ou apenas um paliativo no financiamento da educação infantil?

Considerando a realidade atual do país, o contexto das contradições sociais expressas na violência, na exploração de crianças em situação 
de risco, as necessidades impostas pelas novas tecnologias que chegam cada vez mais rápido atingindo uma população sempre mais jovem e, especialmente, a necessidade de se estimular o processo de humanização em uma sociedade carregada do apelo aos valores de mercado e do consumo, observamos a necessidade de políticas públicas permanentes que atendam à educação infantil, de tal forma a permitir condições favoráveis ao desenvolvimento pleno das novas gerações.

A EDUCAÇÃO INFANTIL NO CONTEXTO HISTÓRICO DO FINANCIAMENTO À EDUCAÇÃO

No Brasil, até o início do século XX, o tratamento dispensado às crianças, particularmente de setores de baixo status socioeconômico e de famílias trabalhadoras, era a visão da assistência social. De certa forma, um misto de assistencialismo e problema de saúde pública. Como, até a década de 1960 do século passado, o percentual feminino no mercado de trabalho e a visão que combinava "rainha do lar" e " função materna" eram determinadas para as mulheres, para o poder público não era prioridade uma política pública permanente para a educação infantil.

A partir da década de 1970, com a participação efetiva das mulheres no mercado de trabalho, as crises econômicas e as mudanças de ordem sociocultural, efetivou-se um processo que já era uma reivindicação dos sindicatos e das associações feministas: a transformação da visão predominante das creches como "depositários de crianças" em locais de sociabilização, contato com atividades pedagógicas e estímulo ao início do desenvolvimento da transição da família para a escola, sem os traumas que tal processo possa causar.

A CF de 1988 garantiu o direito de cidadania às crianças, efetivado pelo Estatuto da Criança e do Adolescente (1990) e, de certa forma, também consolidado a partir da LDB (1996). A luta pelo reconhecimento do direito à educação infantil assumia um caráter jurídico e uma dimensão de política do Estado, saindo do assistencialismo.

Entretanto, se a lei estabelecia os direitos, os custos pagos pela sociedade através dos impostos e gerenciados pelo poder público foram considerados elevados. Num contexto de ajustamento e reformas econômicas baseadas na diminuição do Estado, na desregulamentação e diminuição dos gastos públicos típica dos anos 90 do século XX, a educação infantil viu-se relegada a um plano secundário. 
Faz-se necessário observar também que os orçamentos públicos são verdadeiras "arenas", onde os gastos são determinados pelos grupos que maior poder de pressão dispõem. Desta forma, os setores populares quase sempre são penalizados com os cortes nos gastos públicos e, significativamente, afetando a educação infantil. Castro e Barreto (2003, p. 153) observaram que, de acordo com as metas do PNE e o aumento da população de 0 a 6 anos, seria necessário um acréscimo de $50 \%$ no período de cinco anos (entre 2006 e 2011) nos recursos destinados à educação infantil.

Conforme Pinto (2006), permanece um hiato nas responsabilidades para com a educação infantil entre os entes federativos. A União pouco participa na divisão dos custos. Com o processo de descentralização a partir da década de 1990, os estados foram se desvencilhando dos custos e os municípios, elos mais frágeis no contexto tributário, na medida em que a maioria sobrevive em função das transferências de impostos federais e estaduais, assumiram os custos com a modalidade. O quadro 1 demonstra a participação de estados e municípios com relação às matrículas na educação infantil e no ensino fundamental durante o ano de 2005.

Quadro 1 - Responsabilidades por matrículas na educação infantil e ensino fundamental entre estados e municípios (\%) em 2005

\begin{tabular}{|l|c|c|}
\hline Modalidade & Estados & Municípios \\
\hline Educação infantil & $3,0 \%$ & $97 \%$ \\
\hline Ensino fundamental & $40 \%$ & $60 \%$ \\
\hline
\end{tabular}

Fonte: Pinto (2006, p. 204).

Entre outros aspectos, esta realidade contribui para a limitação da expansão e universalização da educação infantil para a população desta faixa etária. No mesmo estudo, Pinto (2006, p. 205) demonstra o distanciamento no sentido do atendimento à população de crianças dentro do ensino básico (quadro 2). Enquanto a faixa etária de 07 a 14 anos atingiu, praticamente, os percentuais próximos da completa universalização, há substancial queda na população de 04 a 06 anos, aprofundando-se entre as crianças de 0 a 03 anos. No estudo, consideraram-se as matrículas nas redes estadual e municipal, bem como na rede privada. 
Quadro 2 - Atendimento na educação infantil e ensino fundamental [07-14 anos] (\%) conforme faixa etária em 2005

\begin{tabular}{|l|c|c|c|}
\hline Faixa etária & 0 a 3 anos & 04 a 06 anos & 7 a 14 anos \\
\hline $\begin{array}{l}\text { Percentual de atendimento } \\
\text { em 2005 }\end{array}$ & $9,4 \%$ & $61,4 \%$ & $96,4 \%$ \\
\hline
\end{tabular}

Fonte: Pinto (2006, p. 205).

A realidade em tela assume um caráter mais preocupante na medida em que a população de status socioeconômico inferior é mais afetada em função da inexistência de mecanismos permanentes e com suficiência que permitam o pleno desenvolvimento da educação infantil no país. A partir do levantamento realizado pela Ibege (2005) e pesquisa sobre o custo-aluno-qualidade, desenvolvida por Pinto (2006), verificou-se que, em 2000, o setor social situado na faixa que recebe mensalmente até um salário mínimo apresenta-se mais distanciado da educação infantil (quadro 3). Os resultados parecem revelar um apartheid educacional, definido a partir do nascimento.

Quadro 3 - Atendimento na E.I. (0-6 anos) x renda per capita (s. m.) no Brasil em $2000(\%)$

\begin{tabular}{|l|c|}
\hline Renda per capita (salário mínimo) & $\begin{array}{c}\text { População de 0 a 6 anos atendida } \\
\text { na E.I. (\%) }\end{array}$ \\
\hline Sem rendimentos & $22 \%$ \\
\hline Até 0,5 s. m. & $27 \%$ \\
\hline Mais de 0,5 s.m. até 1 s.m. & $32 \%$ \\
\hline Mais de 1 s.m. até 2 s.m. & $38 \%$ \\
\hline Mais de 2 s.m. até 3 s.m. & $45 \%$ \\
\hline Mais de 3 s.m. até 5 s.m. & $51 \%$ \\
\hline Acima de 5 s.m. & $59 \%$ \\
\hline
\end{tabular}

Fonte: IBEGE; Pinto (2006, p. 206)

A POLÍTICA DE FINANCIAMENTO AO ENSINO FUNDAMENTAL: FundEF E A “AUSÊNCIA PRESENTE” DA EDUCAÇÃO INFANTIL

Em que pese a vinculação constitucional de recursos mínimos à educação, conforme disposto nos parágrafos $2^{\circ}$ e $3^{\circ}$ do artigo 211 da $\mathrm{CF}$ e nos artigos $10^{\circ}$ e $11^{\circ}$ da LDB, não há entre os níveis de ensino uma 
distribuição equitativa das verbas. Desta forma, torna-se quase inviável a determinação de que cabe prioritariamente aos municípios a responsabilidade pelo ensino fundamental e aos estados pelo ensino médio. Com base nesta realidade e também em função da agenda internacional da década de 1990 em favor da educação básica, tendo como principal referência a Conferência Mundial de Educação para Todos, realizada em Jomtien, Tailândia, bem como as exigências do PNE e o disposto nas "Disposições transitórias" da CF, determinando que 50\% dos percentuais constitucionais alocados para a educação fossem destinados à erradicação do analfabetismo, criou-se o Fundo de Manutenção e Desenvolvimento do Ensino Fundamental e de Valorização do Magistério (Fundef).

A subvinculação de recursos para o ensino fundamental, determinada pela Emenda Constitucional n. 14/96, posteriormente regulamentada pela Lei n. 9.424, de 24 de dezembro de 1996, que dispunha sobre o Fundef, constituiu-se em uma ruptura num processo histórico de exclusão da maior parcela das crianças e aos adolescentes, particularmente dos setores de baixa renda, quer do acesso, quer da permanência nos níveis básicos de educação (AMARAL, 2002; NEGRI, 1997).

Entretanto, no contexto de suas contradições e limitações, excluía a educação infantil, entre outras modalidades, do aporte de recursos destinados ao ensino fundamental. Diversos autores, educadores, bem como os setores organizados da sociedade, protestaram e denunciaram esta exclusão.

Conforme Melchior (1997, p. 24-25), Machado (2000), a partir do Fundef, os Estados deixaram de investir em educação infantil (CAstro, 1998). Arelaro (2004) destacou o fato de que o processo de descentralização do ensino fundamental, iniciado no final dos anos 90, sobrecarregou os municípios brasileiros, na medida em que o custoaluno não acompanhava sequer a inflação, quanto mais o dispêndio com criação, manutenção e infraestrutura das escolas e, especialmente, com contratação e pagamento de professores (MonleVADE, 1998; DAVIS, 2001). Didonet (2006), Coelho, Barreto et al. (2006) alertaram para o pouco caso com a educação infantil.

Um aspecto observado constituiu-se na valorização dos profissionais do magistério (quadro 4). Tomando os resultados no período 19972001, registrou-se melhoria nos níveis salariais médios dos profissionais do magistério, com reajustes maiores nas redes municipais em todas as regiões, o que é ainda mais significativo quando se leva em conta que 
foi nessas redes que aumentou substancialmente o número de docentes. Os maiores índices foram concedidos aos profissionais dos municípios e das regiões mais pobres, com o que se reduziu a distância entre seus vencimentos e a média das demais regiões e, por fim, os reajustes foram mais expressivos nas jornadas de 20 horas semanais.

Quadro 4 - Estimativa do salário base médio dos professores do ensino fundamental com carga horária de 20 horas semanais, em todas as redes de ensino, por nível de formação Variação em percentagem entre dez./1997 e jun./2001

\begin{tabular}{|l|c|c|}
\hline Região & $\begin{array}{c}\text { Nível médio } \\
\text { Modalidade normal }\end{array}$ & Licenciatura plena \\
\hline Norte & 43,90 & 24,10 \\
\hline Nordeste & 84,00 & 71,60 \\
\hline Sudeste & 18,90 & 11,50 \\
\hline Sul & 39,20 & 41,60 \\
\hline Centro-Oeste & 43,10 & 32,70 \\
\hline Brasil & 44,90 & 31,60 \\
\hline
\end{tabular}

Fonte: MEC - Balanço do Fundef 1998-2002 - Pesquisa FIPE, 2001.

A redistribuição dos recursos públicos, uma das bases fundamentais preconizadas pelo Fundef, foi observada em um estudo do Banco Mundial, no qual é afirmado que

dados de 2001 indicam que dos 5.386 municípios, 2.033 foram "perdedores" líquidos do Fundef, ou seja, contribuíram mais do que receberam, porque tinham poucas escolas e matrículas. A contribuição líquida total dos 'perdedores' foi de, aproximadamente $\mathrm{R} \$ 0,8$ bilhões. 3.342 municípios foram "ganhadores" líquidos e a soma total do ganho líquido foi de aproximadamente R\$3,6 bilhões. (BAnCo Mundial, 2002, p. 28)

O gráfico 1 demonstra a evolução dos recursos destinados ao ensino fundamental através do Fundef no período 1998-2003, que foi afetada por crises externas e pelas políticas de austeridade fiscal e cambial.

Contudo, não existiram investimentos em educação infantil na perspectiva do Fundef. Os parcos recursos federais alocados eram oriundos do Programa de Alimentação Escolar, um programa desenvolvido com recursos do salário educação. Também compunham os recursos 
federais destinados à educação infantil valores dos Planos de Trabalho Anual (PTA).

Gráfico 1 - Evolução dos recursos para a educação fundamental - 1998-2003

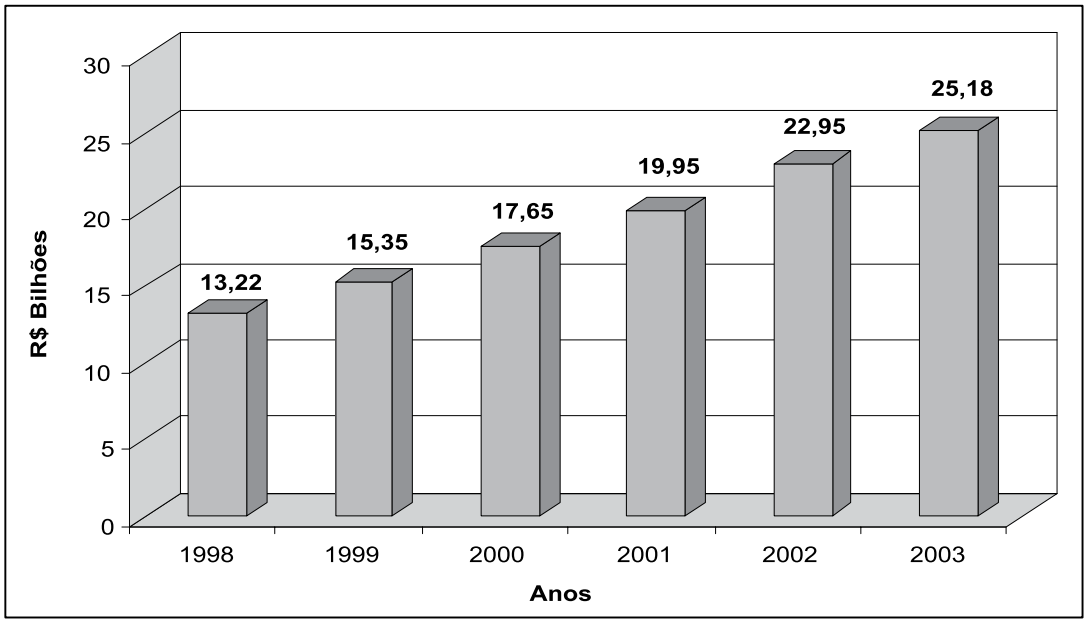

Fonte: Dados originais da STN-MF

O gráfico 2 mostra a evolução do valor mínimo aluno/ano entre 1998 e 2004.

Gráfico 2 - Valor aluno/ano do Fundef (1998-2004)

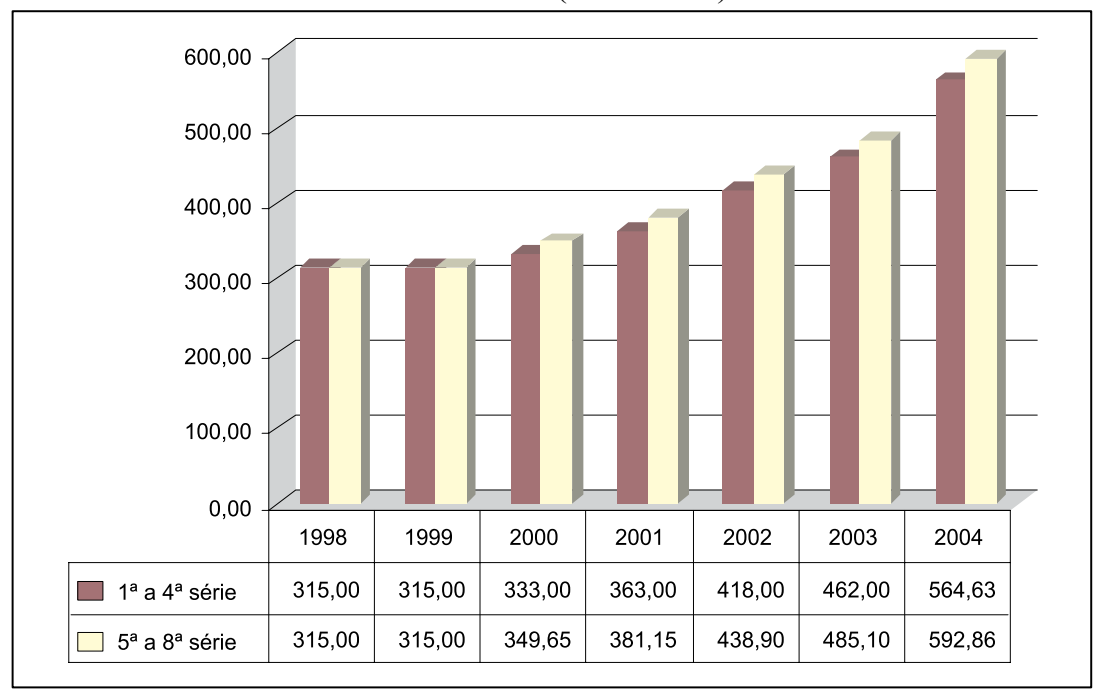

Fonte: MEC-INEP. 


\section{O FundEB E A EDUCAÇÃO INFANTIL}

A proposta de organização do Fundeb tem como base o período compreendido entre 2006 e 2019, uma duração de quatorze anos. Ele abrangerá a educação infantil (creches e pré-escola), o ensino fundamental, o ensino médio, a EJA e a educação especial, que não foram contemplados na criação do Fundef. Estabelece, na proposta atual do Fundeb, a divisão em onze faixas de valores aluno/ano, com uma diferenciação entre as áreas urbanas e rurais, o ensino médio profissionalizante e, um aspecto significativo, contempla as populações indígenas e remanescentes dos antigos refúgios dos escravos negros, denominados "quilombos", que se organizam em comunidades, mantendo aspectos culturais particulares.

Também é destacado o fato de que um mínimo de $60 \%$ dos recursos do fundo será destinado ao pagamento do magistério em efetivo exercício. O objetivo do Fundeb é progressivamente atingir, no quarto ano de vigência, 47,2 milhões de alunos. É reforçada a política de complementação de recursos por parte da União quando os demais entes federativos não conseguirem alcançar o valor mínimo nacionalmente definido. A composição dos recursos do Fundeb mantém basicamente a mesma estrutura anterior (Quadro 5).

Quadro 5 - Comparação entre o Fundef e a proposta do Fundeb. Em US\$ de março de 2006

\begin{tabular}{|c|c|c|c|}
\hline Parâmetro & Fundef & \multicolumn{2}{|l|}{ Fundeb } \\
\hline 1) Vigência & $\begin{array}{l}\text { De } 10 \text { anos (até } \\
\text { 2006) }\end{array}$ & \multicolumn{2}{|c|}{ De 14 anos (após a criação) } \\
\hline 2) Alcance & $\begin{array}{l}\text { Apenas o ensino } \\
\text { fundamental }\end{array}$ & \multicolumn{2}{|c|}{$\begin{array}{l}\text { Educação infantil, ensino fundamental e } \\
\text { médio }\end{array}$} \\
\hline 3) Número de alunos & $\begin{array}{l}30,7 \text { milhões (censo } \\
\text { escolar de 2004) }\end{array}$ & \multicolumn{2}{|c|}{$\begin{array}{l}47,5 \text { milhões de alunos a partir do } 4^{\circ} \text { ano de } \\
\text { vigência do fundo }\end{array}$} \\
\hline $\begin{array}{l}\text { 4) Fontes de recursos } \\
\text { que compõem o } \\
\text { fundo }\end{array}$ & $\begin{array}{l}15 \% \text { dos principais } \\
\text { impostos e de mais } \\
\text { fácil arrecadação }\end{array}$ & $\begin{array}{l}\text { Contribuição } \\
\text { dos estados, DF } \\
\text { e municípios, de } \\
16,25 \% \text { no primeiro } \\
\text { ano até chegar em } \\
20 \% \text { a partir do } \\
\text { quarto ano, sobre os } \\
\text { principais impostos }\end{array}$ & $\begin{array}{l}\text { Contribuição dos } \\
\text { estados, DF e } \\
\text { municípios, de } 5 \% \\
\text { no primeiro ano até } \\
\text { chegar a } 20 \% \text { a partir } \\
\text { do quarto, sobre seus } \\
\text { principais impostos }\end{array}$ \\
\hline
\end{tabular}




\begin{tabular}{|c|c|c|}
\hline Parâmetro & Fundef & Fundeb \\
\hline $\begin{array}{l}\text { 5) Montante de } \\
\text { recursos previstos } \\
\text { (contribuição de } \\
\text { estados, DF e } \\
\text { municípios) }\end{array}$ & $\begin{array}{l}\text { US\$ } 14,51 \text { bilhões } \\
\text { (previsão } 2005 \text { sem } \\
\text { complementação da } \\
\text { União) }\end{array}$ & $\begin{array}{l}\text { Considerando as estimativas (em valores de } \\
\text { 2005): US\$ } 15,95 \text { bilhões no primeiro ano } \\
\text { chegando a US\$ } 20,32 \text { bilhões no quarto ano }\end{array}$ \\
\hline $\begin{array}{l}\text { 6) Complementação } \\
\text { da União }\end{array}$ & $\begin{array}{l}\text { US\$ } 183,9 \text { milhões } \\
\text { (previstos para 2005) }\end{array}$ & $\begin{array}{l}\text { Considerando as estimativas para 2005: US\$ } \\
930,23 \text { milhões no primeiro ano chegando a } \\
2,09 \text { bilhões no quarto ano }\end{array}$ \\
\hline $\begin{array}{l}\text { 7) Total geral de } \\
\text { recursos para o fundo }\end{array}$ & $\begin{array}{l}\text { US\$ } 14,69 \text { bilhões } \\
\text { (previstos para 2005) }\end{array}$ & $\begin{array}{l}\text { Previsões em valores de } 2005 \text { : US } \$ 16,83 \\
\text { bilhões no primeiro ano, chegando a } 22,3 \\
\text { bilhões no quarto ano }\end{array}$ \\
\hline $\begin{array}{l}\text { 8) Distribuição dos } \\
\text { recursos }\end{array}$ & $\begin{array}{l}\text { Com base no número } \\
\text { de alunos do ensino } \\
\text { fundamental regular } \\
\text { e especial, de acordo } \\
\text { com os dados do } \\
\text { censo escolar do ano } \\
\text { anterior }\end{array}$ & $\begin{array}{l}\text { Com base no número de alunos da educação } \\
\text { básica (creche, pré-escola, fundamental e } \\
\text { médio) de acordo com os dados do censo } \\
\text { escolar do ano anterior observada a seguinte } \\
\text { escala: } \\
\text { - Alunos do ensino fundamental regular e } \\
\text { especial: } 100 \% \text { a partir do primeiro ano. } \\
\text { - Alunos da educação infantil, ensino médio e } \\
\text { EJA: } 25 \% \text { no primeiro ano; } 50 \% \text { no segundo } \\
\text { ano; } 75 \% \text { no terceiro ano e } 100 \% \text { a partir do } \\
\text { quarto ano. }\end{array}$ \\
\hline $\begin{array}{l}\text { 10) Valor mínimo } \\
\text { nacional por aluno/ } \\
\text { ano }\end{array}$ & $\begin{array}{l}\text { Fixado anualmente } \\
\text { com diferenciações } \\
\text { entre as séries inicias } \\
\text { e finais e com escolas } \\
\text { urbanas e rurais }\end{array}$ & $\begin{array}{l}\text { Fixado anualmente com diferenciações } \\
\text { previstas para onze faixas de aplicação }\end{array}$ \\
\hline
\end{tabular}

Fonte: Parecer aprovado em 08/12/2005, na Comissão Especial encarregada e analisar a PEC 415/2005, na Câmara dos Deputados.

Em relação à Proposta de Emenda à Constituição Federal n. 415/05, que cria o Fundeb, são apresentadas alguns antagonismos, dentre os quais destacamos: 1) a lógica de construção e aprovação do Fundeb pelo Congresso Nacional manteve praticamente inalteradas as bases do fundo anterior, fundo de natureza contábil, constituído de 27 fundos estaduais, compostos de $20 \%$ de todos os impostos transferidos pela União aos estados e municípios; 2) manteve o aspecto das desigualdades regionais, ao considerar um valor único aluno/ano nacional; 3) com a disputa fiscal que existe hoje entre os entes federativos, a política universalista de expansão da educação pode sofrer dificuldades; 4) questiona-se se a União pode aumentar seu aporte em meio a uma política de ajuste fiscal e pagamento de juros e serviços da dívida pública, questiona-se o quanto poderia ter sido obtido com recursos suplementares e, por fim, 
destacamos o valor aluno/ano que por muitos é considerado ainda inferior ao mínimo necessário.

Para a educação infantil, a principal questão reside no fato de que foi incluída na política de financiamento da educação básica. Entretanto, os recursos destinados mostram-se insuficientes.

\section{QUANTO CUSTA A EDUCAÇÃO INFANTIL?}

Em estudo recente realizado por Verhine e Magalhães (2006), discutindo a perspectiva de financiamento da educação básica no Brasil, os autores propuseram a dimensão do Custo-Aluno Manutenção do Ensino (CA_MAN) e do Ensino Custo-Aluno-Econômico (CA_ECO). Desta forma, o CA_MAN engloba as "categorias de pessoal, material de consumo, material permanente e outros insumos" e o CA_ECO, "além das categorias usadas no cálculo do custo-aluno MAN, considerou as instalações físicas (terreno prédio) e a merenda escolar" (VERHINE; MAGALHÃES, 2006, p. 238). Segundo os autores, o custo-aluno na educação infantil, consideradas as modalidades creche, pré-escola e alfabetização apresentaria a seguinte estimativa: creches, CA_MAN R\$3.093,00 e CA_ECO R\$ 3.841,00; pré-escola, CA_ECO R\$1.665,00 e CA_MAN R\$ 1.465,00; alfabetização, CA_ECO R\$ 947,00 e CA_MAN R\$ 802,00 (Verhine; Magalhães, 2006, p. 242-243).

Considerando a estimativa de custos apresentada, a categoria pessoal (docente e não-docente) tem o percentual mais elevado $(66,75 \%)$ no total, e no setor dos custos-manutenção, o conjunto terreno, prédio e merenda têm o percentual mais elevado (14,29\%), conforme quadro 6 .

Quadro 6 - Estimativa de custos por categoria na E.I. (\%)

\begin{tabular}{|l|c|c|}
\hline Custos & Categorias & Percentuais na E.I. \\
\hline Docente & $38,10 \%$ & \\
\hline Econômico (ECO) & Não-docente & $28,65 \%$ \\
\hline Material de consumo & $11,68 \%$ & \\
\hline Material permanente & $2,90 \%$ & \\
\hline Manutenção (MAN) & Outros insumos & $4,38 \%$ \\
\hline $\begin{array}{l}\text { Outros (terreno, } \\
\text { merenda escolar) }\end{array}$ & $14,38 \%$ & \\
\hline Total & & $\mathbf{1 0 0 , 0 0 \%}$ \\
\hline
\end{tabular}

Fonte: Verhine; Magalhães (2006, p. 245). 
Em outra pesquisa, Farenzena e Machado (2006) obtiveram o custo da educação básica nas escolas públicas municipais, em diversos estados brasileiros durante o ano de 2005 . O estudo teve como referência municípios de todas as regiões do país e envolveu a educação infantil (creches, pré-escola, alfabetização), ensino fundamental (07-14 anos), o ensino médio, a educação de jovens e adultos e também o ensino especial. No caso da educação infantil, destaca-se o fato de que os estados e municípios que apresentam um maior percentual de investimentos situamse nas regiões Sul e Sudeste. Os estados das regiões Norte, Nordeste e Centro-Oeste, com algumas variações, precisam ampliar os percentuais mínimos necessários (quadro 7). Configura-se novamente o apartheid de nascimento, agora também na dimensão regional.

Quadro 7 - Custo-aluno-ano médio (em R\$) na educação infantil (2005)

\begin{tabular}{|l|l|r|r|r|}
\hline \multirow{5}{*}{ Região } & Estado & Creche & Pré-escola & Alfabetização \\
\hline \multirow{5}{*}{ Nordeste } & Bahia & $1.962,85$ & 763,05 & 695,30 \\
\cline { 2 - 5 } & Maranhão & - & 849,14 & 599,93 \\
\cline { 2 - 5 } & Ceará & 543,67 & 411,21 & 420,50 \\
\cline { 2 - 5 } & Paraíba & - & 618,83 & 769,81 \\
\cline { 2 - 5 } & Sergipe & 555,36 & 674,67 & 787,91 \\
\hline \multirow{4}{*}{ Norte } & Amazonas & - & 621,26 & 703,69 \\
\hline \multirow{4}{*}{ Centro-Oeste } & Minas Gerais & $2.341,56$ & 950,40 & 972,98 \\
\cline { 2 - 5 } & São Paulo & $2.767,39$ & $1.238,00$ & $1.499,33$ \\
\cline { 2 - 5 } & Rio de Janeiro & $4.193,53$ & $1.419,60$ & 868,85 \\
\cline { 2 - 5 } & Espírito Santo & - & $1.315,17$ & $1.087,21$ \\
\hline \multirow{3}{*}{ Sul } & Goiás & $1.573,43$ & $1.597,47$ & $1.302,70$ \\
\cline { 2 - 5 } & Mato Grosso & - & 979,27 & 932,54 \\
\cline { 2 - 5 } & Mato Grosso do Sul & & $1.134,20$ & $1.378,27$ \\
\hline \multirow{2}{*}{ Brasil } & Paraná & $2.538,55$ & $1.109,19$ & $1.004,24$ \\
\cline { 2 - 5 } & Santa Catarina & $1.071,57$ & $1.059,74$ & 993,03 \\
\cline { 2 - 5 } & Rio Grande do Sul & $3.325,35$ & $1.469,36$ & $1.154,03$ \\
\hline
\end{tabular}

Fonte: Farenzena, N.; Machado, M.G.F. (2006, p. 283).

\section{CONSIDERAÇÕEs FinAis}

$\mathrm{Na}$ dimensão labiríntica em que se encontra o financiamento da educação no Brasil, particularmente no que diz respeito à educação infantil, constatamos que, mesmo considerando a inclusão da modalidade no Fundeb, permanece um abismo entre o mínimo e o necessário. Além 
disto, deve-se considerar o fato de que, no ano de 2004, o governo federal aplicou na educação infantil R \$26.424.810,00, o que significou 9,21\% a menos que o alocado em 2003. Em 2005, este percentual foi ampliado em 39,47\%, ou seja, no valor de $\mathrm{R} \$ 36.854 .855,00$, mas em relação ao ano de 2004. O interessante é observar que, conforme Carneiro e Mesquita (2006, p. 355), este valor "foi um pouco maior que o investimento realizado em 2002 ( $\mathrm{R} \$ 32.789 .334)$ ).

Neste sentido é necessário registrar que ainda carecem de estudos mais abrangentes o custo-aluno na modalidade e, por outro lado, como observaram Castro e Barreto (2003, p.161-162), continuam "deficientes as informações sobre gastos públicos nos diversos segmentos educacionais".

Observamos também a presença do apartheid educacional que se configura tanto na dimensão do nascimento como na dimensão regional. Em outras palavras, os setores de status socioeconômico inferior estão cada vez mais distantes das possibilidades de inclusão da população infantil na educação infantil. Ao contrário, nos setores com poder aquisitivo maior cresce a tendência a esta inclusão. Novamente, o contexto da situação de risco, da exploração do trabalho infantil e de outras formas de violência, em que pese os programas sociais e de complementação de renda, parece rondar desafiadoramente este setor da população.

Por outro lado, as desigualdades regionais no país mantêm-se fortes e vivas. As regiões Sul e Sudeste aplicam percentuais maiores na educação infantil, enquanto Norte e Nordeste permanecem num limite entre o nada e o muito pouco. Na região Centro-Oeste, mantém-se também percentuais ainda acanhados quando se verifica as reais necessidades de custos da educação infantil.

Na política de financiamento à educação básica, percebemos que o Fundef foi absolutamente omisso no sentido da alocação de verbas à educação infantil. O Fundeb, recém-aprovado no Congresso, embora incluindo a modalidade, apresenta percentuais acanhados no sentido do financiamento. Ainda devemos considerar o fato de que a complementação da União manteve-se no mesmo percentual comparativamente ao Fundef.

Considerando o fato de que os municípios, elo mais frágil na realidade tributária do país, arcam com a maior parcela da educação infantil, e os estados priorizam o ensino fundamental (07-14) anos, caberia à União uma ação mais efetiva junto ao financiamento da educação infantil. 
Tais medidas implicam necessariamente no tratamento da modalidade como uma política pública educacional permanente. Urge romper com a lógica do discurso inócuo, passando à prática sólida, particularmente no momento em que as políticas de ajuste econômico, desmonte do Estado e abandono das questões sociais em prol do mercado passam por um processo de refluxo tanto na América Latina quanto em outras regiões do planeta. Tratar a educação infantil como política de Estado é, entre outros aspectos, possibilitar o desenvolvimento, a sociabilização e a humanização em meio ao contexto da violência, além da construção da cidadania desde a infância.

\section{ABSTRACT}

This exploratory research paper, based on a survey of aggregate data made available at different governmental ministries and agencies as well as the relevant literature, analyzes the investments in Children's Education from 1996, from the setting up of Fundef, to its approval by the National Congress in April 2007. It sets out to help answer certain questions: What is the per capita cost of a child's education in Brazil? What are the responsibilities of the federative constituents in the development and expansion of the modality? Is Fundeb going to be a significant ally or just a palliative in financing children's education? Finally, it is considered necessary to transform children's education into a permanent public policy and to respect the constitutional precepts for the allocation of funding.

Keywords: Children's education. Financing education. Fundeb. Fundef.

\section{NOTA}

1. Sancionada como Lei n. 11.494, de 20 de junho de 2007.

\section{REFERÊNCIAS}

AMARAL, N. C. Um novo Fundef? As idéias e Anísio Teixeira. Educação \& Sociedade, Campinas, v. 12, n. 75, p. 277-290, ago. 2001.

ARELARO, L.; GIL, J. Política de fundos na educação: duas posições. In: LIMA, M. J. R.; DIDONET, V. FUNDEB - avanços na universalização da educação básica. Brasília: MEC-Inep, 2006, p. 71-88.

BANCO MUNDIAL. Educação municipal no Brasil recursos, incentivos e resultados. Disponível em: <http://www.bancomundial.org.br>. Acesso: em 6 jun.2005. 
BRASIL. Ministério da Educação. Balanço do Fundef: 1998-2002. Disponível em: <http://www.mec.gov.br/>. Acesso em: 06 jun. 2005.

BRASIL. Constituição Federal. Brasília: Senado Federal, 2005.

BRASIL. Lei de Diretrizes e Bases da Educação Nacional (Lei n. 9.394, de 20 de dezembro de 1996). Brasília: Editora do Brasil, 1997.

BRASIL, IBGE. Pesquisa Nacional por Amostragem Domiciliar-PNAD. 2005. Disponível em: <http://www.ibge.gov.br>. Acesso em: 15 abr. 2007.

BRASIL. Estatuto da Criança e do Adolescente (Lei n. 8.069, de 13 de julho de 1990). Disponível em: <http://www.planalto.gov.br>. Acesso: em: 14 abr. 2007.

BRASIL. Plano Nacional de Educação - PNE (Lei n. 10.172, de 9 de janeiro de 2002). Disponível em: <www.inep.gov.br>. Acesso em: 14 abr. 2007.

BRASIL, Secretaria do Tesouro Nacional - Ministério da Fazenda. Evolução dos recursos para o ensino fundamental (1998-2003). Disponível em: $<\mathrm{http}: / / \mathrm{www}$. fazenda.gov.br>. Acesso em: 10 out. 2005.

BRASIL, INEP. Valor aluno-ano do Fundef (1997-2004). Disponível em: $<$ http://www.inep.mec.gov.br>. Acesso em: 08 out. 2005.

CARNEIRO, M. E. F.; MESQUITA, M. C. D. O financiamento da educação infantil no Brasil de 2003 a 2006. RBPAE, Porto Alegre, v. 22, n. 2, p. 345-357, jul./dez. 2007.

CASTRO, J. A. de. O Fundo de Manutenção e Desenvolvimento do Ensino Fundamental e de Valorização do Magistério (Fundef) e seu impacto no financiamento do ensino fundamental. Texto para Discussão n. 604. Brasília, Ipea, 1998. $48 \mathrm{p}$.

CASTRO, J. A. de; BARRETO, A R. Alternativas para o financiamento da educação infantil. Anais do Simpósio da Educação infantil: Construindo o Presente. Brasília: Unesco, 2003. p. 139-162.

COELHO, R. C.; BARRETO, A. R. (Orgs.). Financiamento da infantil: perspectivas em debate. Brasília: Unesco, 2004.

DAVIES, N. O Fundef e as verbas da educação. São Paulo: Xamã, 2001.

DIDONET, V. A educação infantil na educação básica. In: LIMA, M. J. R.; DIDONET, V. Fundeb - avanços na universalização da educação básica. Brasília: MEC-Inep, 2006, p. 31-48.

FARENZENA, N.; MACHADO, M. G. F. O custo das escolas públicas municipais: resultados de uma pesquisa e implicações políticas. RBPAE, Porto Alegre, v. 22, n. 2, p. 277-290, jul./dez. 2007. 
MACHADO, L. B. O Fundef: sua implicação no contexto da Educação Básica. Revista de Administração Educacional, Recife, v.1, n. 5, p. 77-83, jan./jun. 2000.

MELCHIOR, J. C. de A. Mudanças no financiamento da educação no Brasil. Campinas, SP: Autores Associados, 1997.

MONLEVADE, J. O Fundef e seus pecados capitais. 2. ed. Ceilândia, DF: Idéia Editora, 1998.

NEGRI, B. O Fundo de Manutenção e Desenvolvimento do Ensino Fundamental e de Valorização do Magistério. Texto para discussão n. 3. Brasília, Inep, 1997.

PINTO, J. M. R. Uma proposta de custo-aluno na educação básica. RBPAE, Porto Alegre, v. 22, n. 2, p. 197-227, jul./dez. 2007.

VERHINE. R. E.; MAGALHÃES, A. L. F. Quanto custa a educação básica de qualidade? RBPAE, Porto Alegre, v. 22, n. 2, p. 229-252, jul./dez. 2007. 